\title{
The microbiome of bulk tank milk: Characterization and associations with somatic cell count and bacterial count
}

\author{
M. X. Rodrigues, ${ }^{*}$ S. F. Lima, $†$ S. G. Canniatti-Brazaca, ${ }^{*}$ and R. C. Bicalhot ${ }^{1}$ \\ *Department of Agroindustry, Food and Nutrition, Luiz de Queiroz College of Agriculture, University of São Paulo, Piracicaba, SP 13418-900, \\ Brazil \\ †Department of Population Medicine and Diagnostic Sciences, College of Veterinary Medicine, Cornell University, Ithaca, NY 14853
}

\begin{abstract}
Numerous studies have evaluated associations between bacterial groups and milk quality parameters. However, to our knowledge, no research has been published that has analyzed associations between the microbiome and quality parameters of bulk tank milk (BTM). Thus, the aims of this study were to identify the core microbiome of BTM and to examine associations between the microbiome and milk quality parameters. Four hundred seventy-two BTM samples from 19 different dairy farms located in New York State were analyzed by nextgeneration sequencing and quantitative $\mathrm{PCR}$ of the $16 \mathrm{~S}$ rRNA gene to assess the milk microbiome and measure total bacterial load, respectively. Flow cytometry was used to determine bacterial and somatic cell counts. Heatmaps were constructed and simple linear regressions and response screening analysis were performed. To facilitate data analysis and interpretation of the results, we dichotomized the BTM samples into high (HSCC, > 200,000) and low somatic cell count (LSCC, $\leq 200,000)$ and into high (HSPC, $>3.6$ ) and low $\log _{10}$ SPC (LSPC, $\leq 3.6$ ). Spoilage-causing, spore-forming, and pathogenic bacteria of importance to the dairy industry were identified in the core microbiome. In addition, the taxa Thermoanaerobacterium and 5-7N15 were identified in the core microbiome; to our knowledge, these genera have not been previously identified in milk samples. Several bacterial genera were encountered in significantly higher relative abundances in the HSCC group when compared with the LSCC group, including Corynebacterium, Streptococcus, Lactobacillus, Coxiella, Arthrobacter, and Lactococcus. Additionally, several bacterial taxa were found in significantly higher relative abundances in the HSPC groups versus the LSPC groups: Acinetobacter, Enterobacteriaceae, Corynebac-
\end{abstract}

Received May 31, 2016.

Accepted December 15, 2016.

${ }^{1}$ Corresponding author: rcb28@cornell.edu terium, and Streptococcus. In addition, Streptococcus was highly correlated with HSPC, and this genus was the second most abundant bacterial taxon detected in samples classified as HSCC. Bacterial diversity (Shannon index) was negatively correlated with bacterial load, suggesting that the microbiomes of high-bacterial load BTM samples are dominated by smaller groups of bacterial taxa. In conclusion, the associations described corroborated current knowledge about pathogens and spoilage bacteria in relationship to milk quality, and also indicated that other bacterial taxa should be a focus of further investigations.

Key words: milk, microbiome, quality, next-generation sequencing, Streptococcus

\section{INTRODUCTION}

Ensuring the safety and quality of raw milk is a challenge worldwide (Gschwendtner et al., 2016). Since the 1990s, bulk tank milk (BTM) has been used to diagnose current and potential problems in dairy herds related to milk quality and mastitis (Jayarao et al., 2004). In addition, the food industry and cooperatives have been using BTM analysis to identify higher quality milk for which they pay premium prices (Jayarao et al., 2004; Barbano et al., 2006) based on one or more parameters (Gillespie et al., 2012). Nightingale et al. (2008) evaluated the effect of a premium program for high-quality milk in a United States cooperative focused on BTM SCC, which is a widely used criterion for milk quality premium payments (Barbano et al., 2006). Somatic cells are naturally present in milk (Li et al., 2014); commonly, SCC has been used to indicate the prevalence of IMI in dairy herds (Gillespie et al., 2012) and overall milk quality (Li et al., 2014). Associations among milk components, milk quality parameters, and presence of bacteria have been evaluated elsewhere (Park et al., 2007; Katholm et al., 2012).

Milk quality is influenced by several bacterial counts; for example, laboratory pasteurization count and SPC (Gillespie et al., 2012). A high SPC in raw milk indicates mastitis occurrence and problems in milking or general 
hygiene (Gillespie et al., 2012). Microbial contamination of BTM can occur through several sources and by distinct microorganisms (Elmoslemany et al., 2009). Among the microorganisms, spore-forming bacteria is a concern (Barbano et al., 2006); raw milk is a source of endospores produced by mesophilic, thermophilic, and psychrotolerant spore-forming bacteria (Miller et al., 2015). Standard laboratory analysis (based on traditional culturing) following pasteurization is a good technique to indicate the level of spores (Barbano et al., 2006). The majority of microbiological analyses of raw milk microbiota have been based on culture-dependent methods (Fricker et al., 2011); however, culture-dependent methods have several limitations when compared with culture-independent methods (e.g., viable but nonculturable cells cannot be identified by culturing; Weber et al., 2014). Consequently, the use of different culture-independent methods to describe the bacterial composition has emerged. The composition of the bacterial community of raw milk has been described using different culture-independent methods (Kuang et al., 2009; Oikonomou et al., 2014; Weber et al., 2014); however, it is believed that a knowledge gap still exists in our understanding of native bacterial communities in raw milk (Fricker et al., 2011). Moreover, to our knowledge, no research has been published that has analyzed associations between the microbiome and quality parameters of BTM. Therefore, we hypothesized that the bulk tank milk microbiome will be associated with milk quality parameters (e.g., SCC and SPC).

\section{MATERIALS AND METHODS}

\section{BTM Samples Collection}

Dairy farms associated with Cayuga Marketing LLC (central region, NY), which regularly send BTM samples to Dairy One Co-op Inc. (Ithaca, NY) for milk analyses, were invited to participate in this study. Letters of consent were sent to the dairy farmers requesting permission to collect BTM samples to perform milk microbiome analyses and to use data from milk analyses carried out by Dairy One. From 29 members contacted, 19 dairy farms agreed to participate in the research, from which 472 BTM samples were obtained during the study period, September to October 2015. Trained employees collected milk samples from bulk tanks aseptically into vials, which were stored under refrigeration during transport to Dairy One Milk Laboratory. The samples submitted to Dairy One were subjected to milk quality analysis, and aliquots aseptically collected from those samples (approximately $6 \mathrm{~mL}$ ) were sent, under refrigeration, to our laboratory at Cornell University
(Ithaca, NY). The samples were received within $48 \mathrm{~h}$ after collection at the farms, and farm, tank, and date were recorded on a spread sheet. Samples were stored at $-20^{\circ} \mathrm{C}$ for downstream molecular analysis.

\section{SCC and Total Bacteria Count}

The SCC and total bacterial count measurements were carried out at Dairy One Milk Laboratory. The SCC was determined by flow cytometry using a Fossomatic FC Somatic Cell Counter (Foss, Hillerød, Denmark). Briefly, a mixture of each sample and staining solution was prepared, passed through a flow cell in which somatic cells emit fluorescent light pulses, and the fluorescent light pulses were counted (cells $/ \mathrm{mL}$ ). Total bacterial count was determined using a BactoScan FC+ instrument (Foss), which is also based on flow cytometry. The results for individual bacterial count were converted to colony-forming units by BactoScan FC+ software (Foss), considering SPC as reference method (International Dairy Federation, 1991; IDF Standard 100B: 1991, the reference or anchor method applied in this technology); SPC was used to express the final results for total bacterial count.

\section{Next-Generation Sequencing of the Bacterial $16 S$ rRNA Gene}

The DNA was extracted from all samples using a PowerFood Microbial DNA Isolation Kit (MO BIO Laboratory Inc., Carlsbad, CA) following the manufacturer's protocol. The V4 hypervariable region of the bacterial/archaeal 16S rRNA gene was amplified by PCR according to a previously described protocol and optimized for the Illumina MiSeq platform (Caporaso et al., 2012) using different 12-bp error-correcting Golay barcodes for the $16 \mathrm{~S}$ rRNA gene PCR (Lima et al., 2015). The PCR were performed using $10 \mu M$ of each primer (515F and 806R), EconoTaq Plus Green $1 \times$ Master Mix (Lucigen, Middleton, WI), 5 to $50 \mathrm{ng}$ of individual metagenomic DNA samples, and ultrapure water to bring the final reaction volume to 25 $\mu \mathrm{L}$. Blank controls in which no DNA was added to the reaction were also performed. All reactions were set up in triplicate, and the PCR conditions for amplification included an initial denaturing step of $94^{\circ} \mathrm{C}$ for $3 \mathrm{~min}$ followed by 35 cycles of $94^{\circ} \mathrm{C}$ for $45 \mathrm{~s}, 50^{\circ} \mathrm{C}$ for $1 \mathrm{~min}$, and $72^{\circ} \mathrm{C}$ for $90 \mathrm{~s}$, and a final elongation step of $72^{\circ} \mathrm{C}$ for $10 \mathrm{~min}$. Replicates were pooled and the amplified DNA visualized by electrophoresis using $1.2 \%$ (wt/vol) agarose gels stained with $0.5 \mathrm{mg} / \mathrm{mL}$ of ethidium bromide. The DNA was purified using a Gel/PCR Fragments Extraction Kit (IBI Scientific, Peosta, IA). Quantifica- 
tion of purified DNA was carried out using a NanoDrop ND-1000 spectrophotometer (NanoDrop Technologies, Rockland, DE). All samples were standardized to the same DNA concentration and pooled for sequencing on the Illumina MiSeq platform (Illumina Inc., San Diego, $\mathrm{CA}$ ) in 2 different runs according to individual barcode primers. Final equimolar libraries were prepared and sequenced using the MiSeq Reagent Kit V2-300 cycles (Illumina Inc.).

\section{Quantitative PCR}

For assessment of the total bacterial load by quantitative (q) PCR, a subsample of 120 samples was randomly selected. For determination of bacterial load, a plasmid containing the amplified V6 hypervariable region was cloned into TOP10 cells using a Zero Blunt TOPO PCR cloning kit (Life Technologies, Darmstadt, Germany). Plasmid was purified with the QIAprep Spin Miniprep Kit (Qiagen, Valencia, CA) and quantified using Quant-iT PicoGreen and a dsDNA Broad Range Assay Kit (Life Technologies Corporation, Carlsbad, CA). Insertion of the DNA fragment was confirmed by agarose gel electrophoresis, and by sequencing at the Cornell University Life Science Core Laboratories Center. The 16S rRNA copy numbers were measured by qPCR using forward 5'-TGGAGCATGTGGTTTAATTCGA-3' and reverse 5'-TGCGGGACTTAACCCAACA-3' primers previously described (Nonnenmacher et al., 2004). Reactions were performed in $15-\mu \mathrm{L}$ volumes composed of $1 \times$ iQ Sybr Green Supermix (Bio-Rad Laboratories, Hercules, CA), $300 \mathrm{n} M$ of each primer, and $5 \mathrm{pg}$ to 50 ng of genomic DNA (or plasmid DNA standards). The thermal cycler conditions were denaturation at $95^{\circ} \mathrm{C}$ for 3 min, 40 amplification cycles $\left(95^{\circ} \mathrm{C}\right.$ for $10 \mathrm{~s}, 55^{\circ} \mathrm{C}$ for $30 \mathrm{~s}$ ), and 2 final steps at $95^{\circ} \mathrm{C}$ for $1 \mathrm{~min}$ and $55^{\circ} \mathrm{C}$ for 1 min followed by melting curve analysis. All reactions were performed in duplicate (plasmid standards, BTM samples, and blank control) using a MyiQ Real-Time PCR Detection System (Bio-Rad Laboratories). Quantification of $16 \mathrm{~S}$ rRNA target DNA was achieved by 10 -fold serial dilutions, ranging from $10^{0}$ to $10^{7}$ plasmid copies of the previously quantified plasmid standard. The average of the cycle threshold value was used for calculation of the bacterial load.

\section{Bioinformatics and Statistical Analysis}

The 16S rRNA sequences obtained were processed through the open-source pipeline Quantitative Insights into Microbial Ecology (QIIME; version 1.7.0-dev; Caporaso et al., 2010). Sequences were filtered for quality using established guidelines (Bokulich et al., 2013) and were binned into operational taxonomic units (OTU) based on 97\% identity using UCLUST (Edgar, 2010) against the Greengenes reference database (McDonald et al., 2012; May 2013 release). Chimeric sequences were removed, and low-abundance clusters were filtered using USEARCH (Edgar, 2010). The representative sequences for each OTU were compared against the Greengenes database for taxonomy assignment, and only full-length, high-quality reads $(\mathrm{r}=0)$ were used for analysis. Shannon diversity index output was generated by the QIIME pipeline. Before estimating the Shannon index, all sample libraries were rarefied to an equal depth of 10,000 sequences using QIIME.

The OTU data obtained from bioinformatics analyses were used to describe the most abundant phyla of BTM samples in terms of relative abundance (\%), and the data also were used to generate heatmaps to describe the BTM core microbiome and the 30 most abundant bacterial taxa. Analysis of associations between bacterial taxon and milk quality parameters were first performed using the heatmaps according to quartiles of SCC (quartile $1=54,000$ cells $/ \mathrm{mL}$; quartile $2=$ 120,000 cells $/ \mathrm{mL}$; quartile $3=170,000$ cells $/ \mathrm{mL}$; and quartile $4=450,000$ cells $/ \mathrm{mL}$ ) and $\log _{10}$ of the SPC (quartile $1=3.0 \log \mathrm{cfu} / \mathrm{mL}$; quartile $2=3.0 \log \mathrm{cfu} /$ $\mathrm{mL}$; quartile $3=3.60 \log \mathrm{cfu} / \mathrm{mL}$; and quartile $4=5.07$ $\log \mathrm{cfu} / \mathrm{mL})$. The heatmaps were plotted using Cell Plot in JMP Pro 11 (SAS Institute Inc., Cary, NC). Using JMP Pro 11, mean, standard deviation, and range of SCC and of $\log _{10}$ SPC were calculated per dairy farm. Response screening analysis was performed in JMP Pro 11; according to the JMP Pro 11 software, this method "fit a large number of $\mathrm{y}$ by $\mathrm{x}$ combinations to get an idea of what affects what." Therefore, this method was used to determine which bacterial taxa were most associated or most important to high SCC (HSCC; $>200,000$ cells/mL), low SCC (LSCC; $\leq 200,000$ cells/ $\mathrm{mL}$ ), high $\log _{10}$ SPC (HSPC; >3.6 log $\mathrm{cfu} / \mathrm{mL}$ ), and low $\log _{10}$-SPC (LSPC; $\left.\leq 3.6 \log \mathrm{cfu} / \mathrm{mL}\right)$. The 200 most prevalent OTU were added as outcome variables and the dichotomized SCC variable was added as the dependent variable; the same procedure was performed using $\log _{10}$ SPC. $P$-values were adjusted for false discovery rate (FDR) (Benjamini and Hochberg, 1995) and presented as FDR $\log$ Worth (i.e., $-\log _{10} P$-value). The mean relative abundance for each bacterial taxon observed in the BTM samples was used as a reference for calculation of fold changes. The effect size was explored because it shows the magnitude of the difference found. Operational taxonomic units statistically significant on the response screening analysis $\left(\log _{10}\right.$ of the FDR $\geq 1.3$ ) are presented; bacterial taxa with higher relative abundance in HSCC compared with LSCC samples and 
bacterial taxa with higher relative abundance in LSCC compared with HSCC samples were shown in graphics (mean relative abundance $\pm \mathrm{SEM}$ ); the same procedure was also applied to $\log _{10}$ SPC. Simple linear regressions between $\log _{10}$ SPC and Shannon diversity index were assessed using JMP Pro 11 software $(P$-value $<0.001)$. Simple linear regressions were also fitted in JMP software to assess the association between the total bacterial load ( $\log _{10}$ copy numbers of the $16 \mathrm{~S}$ rRNA gene) and 4 factors evaluated: Shannon index, $\log _{10}$ SPC, relative abundance of Enterobacteriaceae, and relative abundance of Acinetobacter (an initial screening was performed and these 2 bacterial taxa presented the highest associations with total bacterial load).

\section{RESULTS}

\section{Sequencing Results, Prevalence of Bacterial Taxa, and Core Microbiome}

Quality filtered reads for the $16 \mathrm{~S}$ rRNA sequences were de-multiplexed, yielding 24,509,428 raw sequences in total (median $=45,821$; range $=6,977-158,311$ ), with a median length of 301 bases per read and an average of 51,965 sequences per sample. The most prevalent bacterial phyla were Firmicutes, Fusobacteria, Bacteroidetes, Proteobacteria, Spirochaetes, and Tenericutes; the mean relative abundance of each phylum by farm is depicted in Figure 1. The 30 most prevalent OTU identified in the BTM samples from each farm are shown in Figure 2. The core microbiome across the 19 farms studied is composed of Ruminococcaceae, Acinetobacter,
Clostridiales, Bacteroidales, 5-7N15, Pseudomonas, Staphylococcus, Lachnospiraceae, Corynebacterium, Planococcaceae, Bacillus, and Thermoanaerobacterium (Figure 3).

\section{Milk Quality Parameters, Bacterial Load by qPCR, and Bacterial Taxa Associations}

The mean, standard deviation, and range of SCC and $\log _{10}$ SPC are shown in Table 1. Associations between SCC quartiles or $\log _{10}$ SPC quartiles and mean relative abundance of the 12 most common OTU identified in the BTM samples were assessed (Figure 4). The relative abundances of Acinetobacter, Enterobacteriaceae, and Streptococcus were higher in the highest quartile of $\log _{10}$ SPC in comparison to the lower $\log _{10}$ SPC groups (Figure 4A). Regarding SCC, Enterobacteriaceae was identified with a higher relative abundance in the fourth quartile than in the other quartiles, as was Corynebacterium, and the mean relative abundance of Streptococcus also increased with the increase in SCC (from the first quartile to the fourth quartile).

Screening analysis was performed to identify the main microbial types distinguishing the microbiomes in samples classified as HSCC and LSSC and $\log _{10}$ SPC. Figure 5 shows the OTU significantly associated with HSCC and LSCC. In HSCC, Coxiella, Dermacoccus, and Lactococcus had higher effect sizes, whereas Corynebacterium and Streptococcus were the most abundant (Figure 5). Ruminococcaceae, Clostridiales, and Bacteroidales were the bacterial taxa with the highest abundances in the HSCC category. More detailed analyses

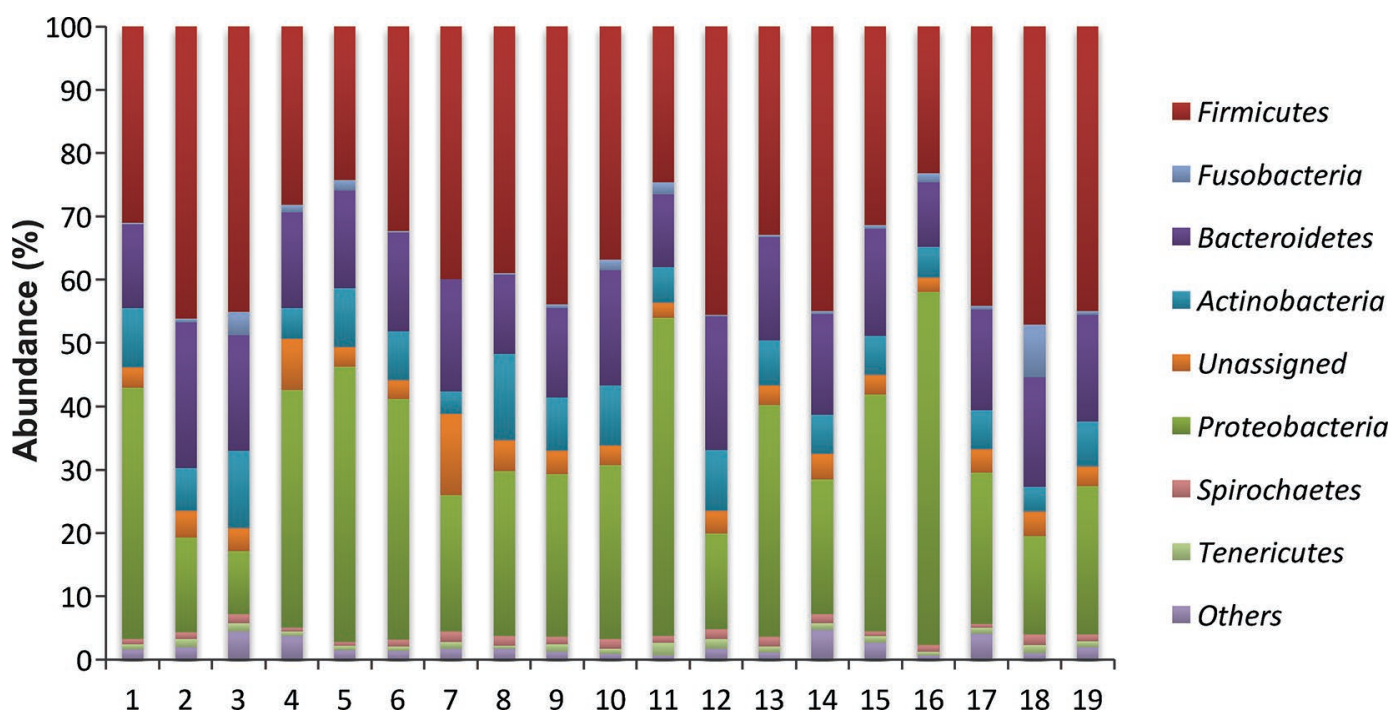

Figure 1. Mean relative abundance of the most prevalent bacterial phyla identified in milk samples of 19 farms studied. Color version available online. 


\section{OTU}

$f$ Ruminococcaceae

g_Acinetobacter

Unassigned

$f$ Enterobacteriaceae

-_Clostridiales

- Bacteroidales

g_5-7NI5

g_Pseudomonas

g_Staphylococcus

f_Lachnospiracees

g_Corynebacterium

g_Streptococcus

g_Treponema

$f$ Rikenellaceae

g_Helcococcus

$f$ Planococcaceae

g_CF231

f_Enterobacteriaceae 2

g_Bacilhus 2

g_Ruminobacter

g_Oscillospira

o_Clostridiales 2

g_Prevotella

$f \_$RF16

g_Coprococcus

o_RF39

f_Leptotrichiaceae

g_Lactobacillus

g_Psychrobacter

$g$ Arthrobacter $\begin{array}{lllllllllllllllllll}1 & 2 & 3 & 4 & 5 & 6 & 7 & 8 & 9 & 10 & 11 & 12 & 13 & 14 & 15 & 16 & 17 & 18 & 19\end{array}$

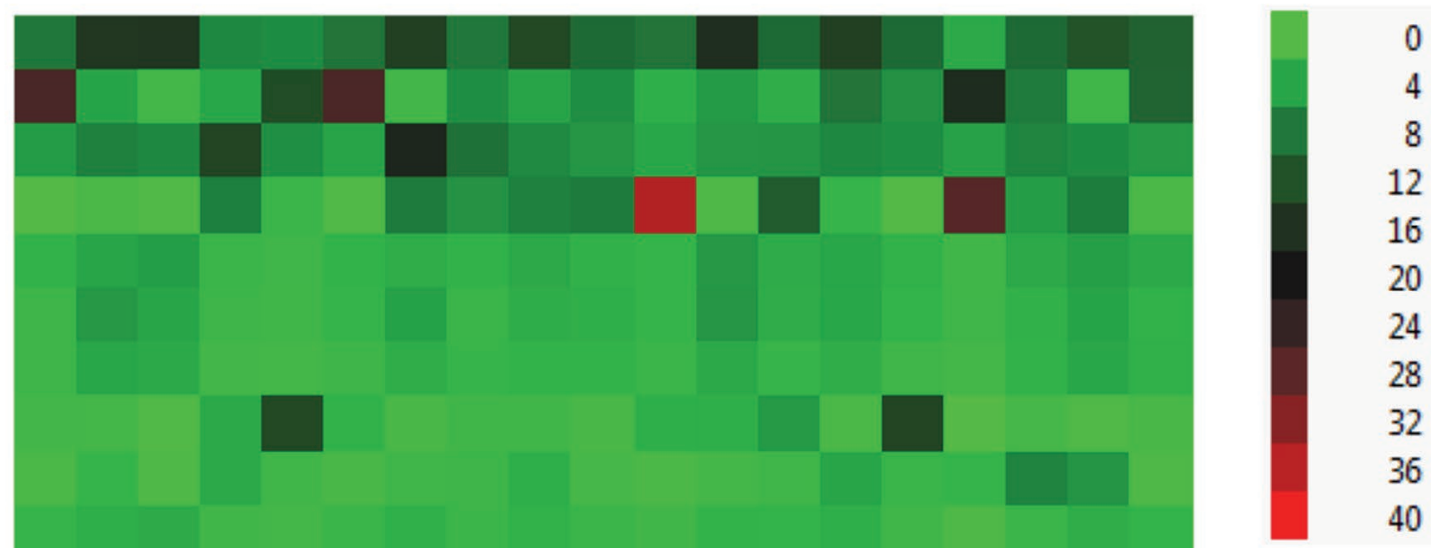

Figure 2. Heatmap illustrating the relative abundance of the 30 most prevalent bacterial taxa in bulk tank milk from the 19 dairy farms enrolled in this study. Each square in the heat map represents the abundance level of a single category. Small relative abundance values are represented by light green, progressing to higher values as black and dark red. The letters in front of the bacterial names identify the lowest level of classification ( $\mathrm{k}=$ kingdom, $\mathrm{p}=$ phylum, $\mathrm{c}=$ class, $\mathrm{o}=$ order, $\mathrm{f}=$ family, and $\mathrm{g}=$ genus). OTU = operational taxonomic units. Color version available online.

were performed using OTU classified as statistically significant $\left(\log _{10}\right.$ of the FDR $\left.\geq 1.3\right)$ in the response screening analysis for the HSCC (Figure 6) and LSCC categories (Figure 7). The effect of milk microbiome on $\log _{10}$ SPC was also evaluated using response screening analysis (Figure 8). In HSPC, the Streptococcus genus had the highest effect size whereas the most abundant bacterial taxa were Acinetobacter and Enterobacteriaceae (Figure 8). In LSPC, Thermoanaerobacterium and Bacillus had the highest effect sizes, whereas Ruminococcaceae, Clostridiales, Bacteroidales, and Staphylococcus were the most abundant bacterial taxa. Detailed 
OTU

$\begin{array}{lllllllllllllllllll}1 & 2 & 3 & 4 & 5 & 6 & 7 & 8 & 9 & 10 & 11 & 12 & 13 & 14 & 15 & 16 & 17 & 18 & 19\end{array}$

f_Ruminococcaceae

g_Acinetobacter

o__Clostridiales

o_Bacteroidales

g_ 5-7N15

g_Pseudomonas

g_ Staphylococcus

$f$ Lachnospiraceae

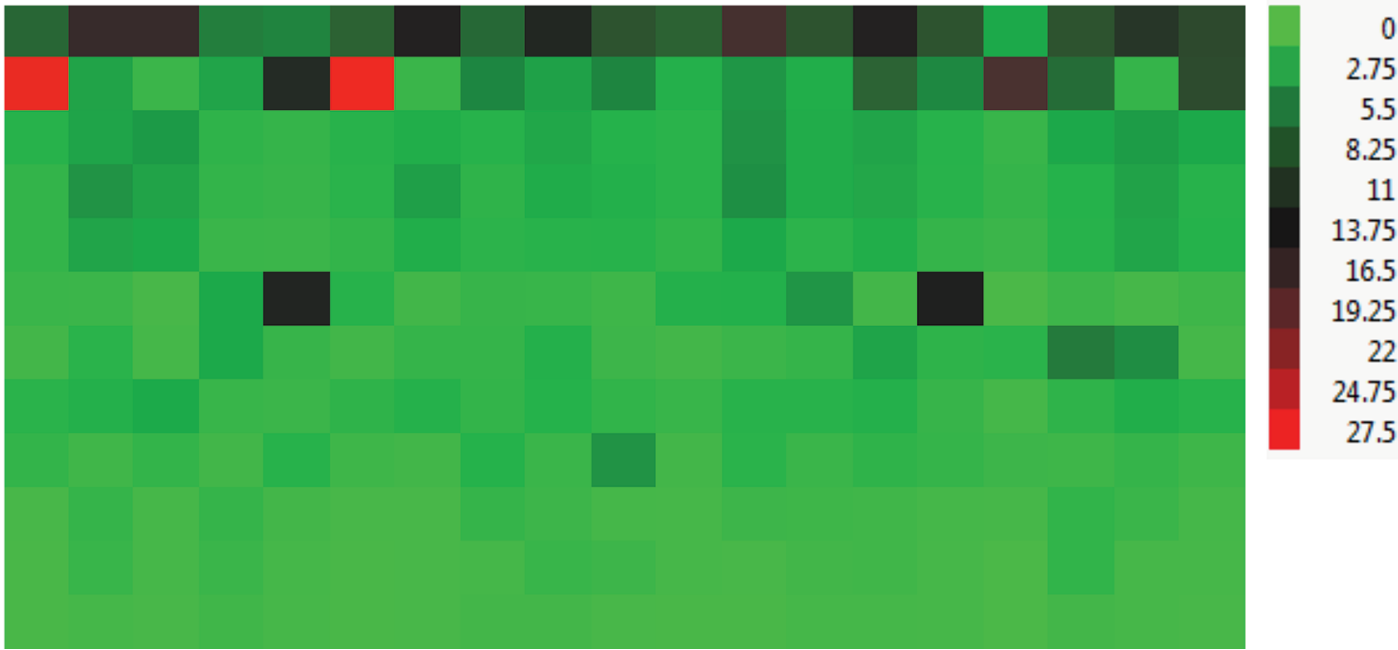

$g$ _ Corynebacterium

f_Planococcaceae

g_Bacillus 2

g_ Thermoanaerobacterium

Figure 3. The bulk tank milk core microbiome, defined as the bacterial taxa detected in all bulk tank milk samples across all 19 farms enrolled in this study. Each square in the heat map represents the abundance level of a single category. Small relative abundance values are represented by light green, progressing to higher values as black and dark red. The letters in front of the bacterial names identify the lowest level of classification ( $\mathrm{k}=$ kingdom, $\mathrm{p}=$ phylum, $\mathrm{c}=$ class, $\mathrm{o}=$ order, $\mathrm{f}=$ family, and $\mathrm{g}=$ genus). OTU $=$ operational taxonomic units. Color version available online.

analysis was performed using bacterial taxa statistically significant in the response screening in the HSPC (Figure 9) and LSPC categories (Figure 10).

$\log _{10}$ SPC and Shannon index were linearly correlated (Figure 11); bacterial taxa diversity decreased with higher values of $\log _{10}$ SPC. The total bacterial load $\left(\log _{10}\right.$ of the number of $16 \mathrm{~S}$ rRNA gene copies) was positively and linearly correlated with the relative abundances of Acinetobacter and Enterobacteriaceae, as well as with $\log _{10}$ SPC (Figure 12A, B, and D). Additionally, a negative correlation was detected between the total bacterial load and the Shannon diversity index (Figure 12C).

\section{DISCUSSION}

To our knowledge, this is the first report to have described associations between the BTM bacterial com-

Table 1. Number of samples (N), mean, SD, and range of $\log _{10}$ SPC and SCC per dairy farm enrolled in this study

\begin{tabular}{|c|c|c|c|c|c|c|c|}
\hline \multirow{2}{*}{$\begin{array}{l}\text { Dairy } \\
\text { farm }\end{array}$} & \multirow[b]{2}{*}{$\mathrm{N}$} & \multicolumn{3}{|c|}{$\log _{10} \mathrm{SPC}$} & \multicolumn{3}{|c|}{$\mathrm{SCC}$} \\
\hline & & Mean & $\mathrm{SD}$ & Range & Mean & $\mathrm{SD}$ & Range \\
\hline 1 & 11 & 4.04 & 0.14 & 0.47 & 73,545 & 8,298 & 34,000 \\
\hline 2 & 22 & 3.04 & 0.10 & 0.30 & 134,285 & 12,071 & 50,000 \\
\hline 3 & 16 & 3.38 & 0.22 & 0.69 & 147,500 & 19,148 & 70,000 \\
\hline 4 & 24 & 3.11 & 0.26 & 0.90 & 140,833 & 23,759 & 100,000 \\
\hline 5 & 24 & 3.31 & 0.31 & 1.51 & 167,500 & 19,615 & 90,000 \\
\hline 6 & 16 & 4.11 & 0.61 & 1.77 & 120,437 & 16,382 & 53,000 \\
\hline 7 & 8 & 3.84 & 0.53 & 1.77 & 162,500 & 16,690 & 40,000 \\
\hline 8 & 19 & 3.43 & 0.25 & 0.84 & 240,000 & 19,148 & 70,000 \\
\hline 9 & 50 & 3.37 & 0.33 & 1.30 & 157,800 & 14,468 & 60,000 \\
\hline 10 & 72 & 3.60 & 0.37 & 1.89 & 203,472 & 68,116 & 330,000 \\
\hline 11 & 18 & 3.88 & 0.35 & 1.46 & 176,833 & 37,281 & 167,000 \\
\hline 12 & 13 & 3.40 & 0.19 & 0.69 & 121,538 & 23,666 & 760,00 \\
\hline 13 & 29 & 3.25 & 0.23 & 0.77 & 151,724 & 16,051 & 600,00 \\
\hline 14 & 55 & 3.51 & 0.38 & 1.47 & 162,000 & 27,514 & 140,000 \\
\hline 15 & 12 & 3.07 & 0.13 & 0.30 & 120,416 & 15,733 & 45,000 \\
\hline 16 & 1 & 3.90 & - & - & 240,000 & - & - \\
\hline 17 & 23 & 3.01 & 0.06 & 0.30 & 80,260 & 8,491 & 32,000 \\
\hline 18 & 25 & 3.26 & 0.16 & 0.47 & 123,520 & 16,676 & 62,000 \\
\hline 19 & 34 & 3.44 & 0.31 & 1.17 & 77,529 & 11,602 & 52,000 \\
\hline
\end{tabular}


(A)

OTU

$f$ _Ruminococcaceae

g_Acinetobacter

Unassigned

$f$ Enterobacteriaceae

o_Clostridiales

- Bacteroidales

g_5_7N15

g_Pseudomonas

g_Staphylococcus

f_Lachnospiracese

g_Corynebacterium

g_Streptococcus
1

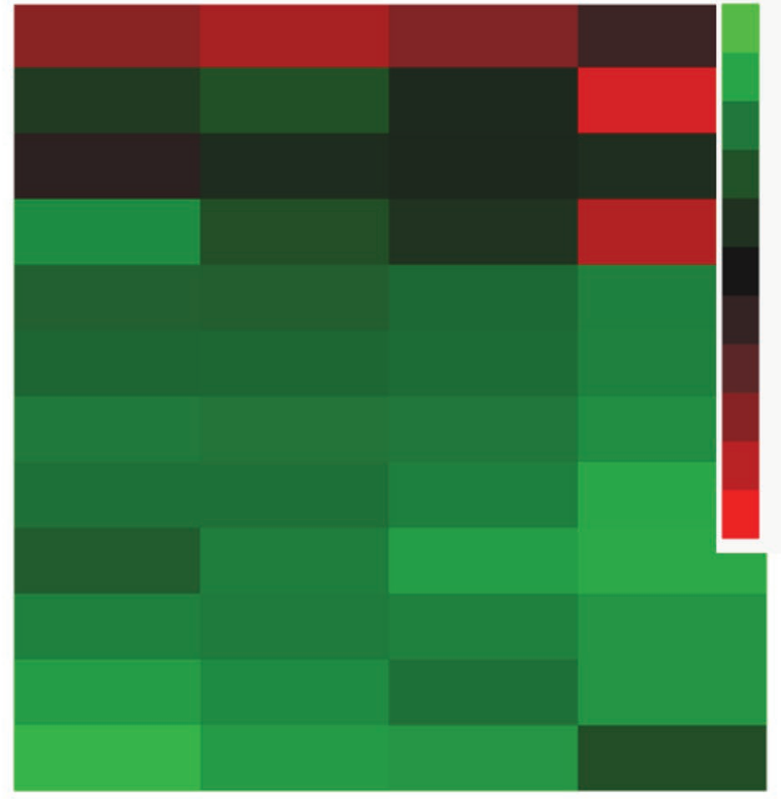

\section{0}

1.4

2.8

4.2

5.6

7

8.4

9.8

11.2

12.6

14

(B)

\section{OTU}

f_Ruminococcaceae

g_Acinetobacter

Unassigned

$f$ Enterobacteriaceae

o_Clostridiales

o_Bacteroidales

g_5_7N15

g_Pseudomonas

g_Staphylococcus

$f$ Lachnospiracese

g_Corynebacterium

g_Streptococcus
1

2

3

4

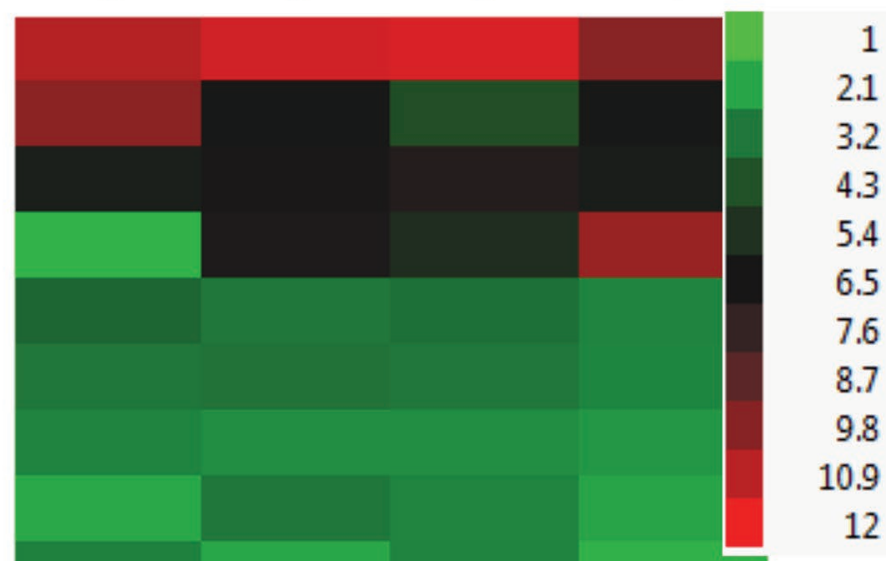

Figure 4. Heat maps illustrating the mean relative abundance of the 12 most common bacterial taxa relative to $\log _{10}$ of the $\mathrm{SPC}(\mathrm{A})$ and SCC (B) quartiles for all milk samples evaluated in this study. Each square in the heat map represents the abundance level of a single category. Small relative abundance values are represented by light green, progressing to higher values as black and dark red. The letters in front of the bacterial names identify the lowest level of classification $(\mathrm{k}=$ kingdom, $\mathrm{p}=$ phylum, $\mathrm{c}=$ class, $\mathrm{o}=$ order, $\mathrm{f}=$ family, and $\mathrm{g}=$ genus $)$. OTU $=$ operational taxonomic units. Color version available online. 


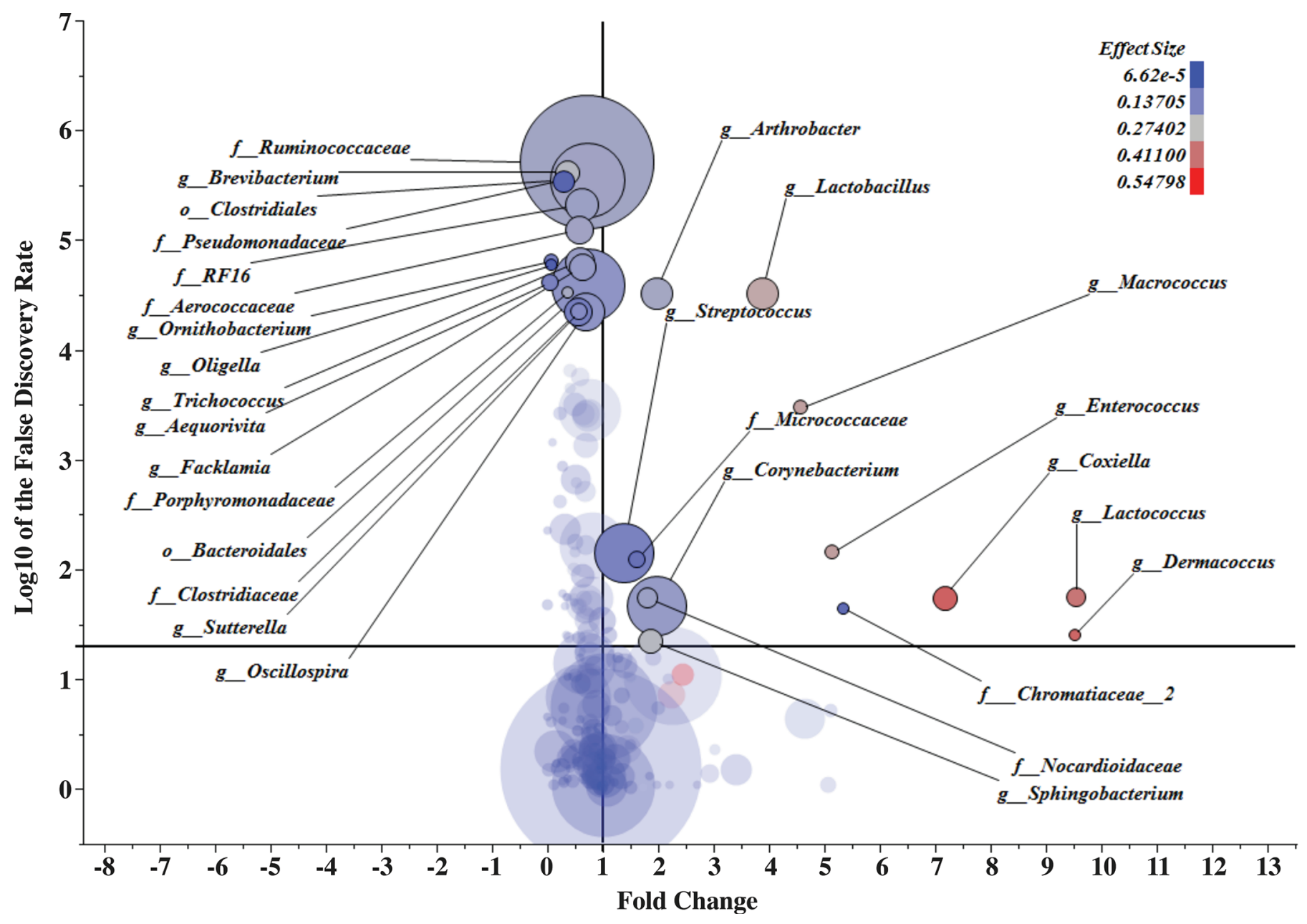

Figure 5. Bubble graph illustrating the operational taxonomic units (OTU) that were significantly associated with SCC. Bulk tank milk samples were divided into high $(>200,000)$ and low SCC $(\leq 200,000)$. The graph illustrates the $\log _{10}$ of the false discovery rate along the y-axis, and the fold change of the relative abundance of the each specific OTU comparing high- versus low-SCC samples along the X-axis. The size of the bubbles represents the overall abundance of each OTU and the colors represent the size of the detected effect (blue $=$ small effect and red $=$ large effect). OTU with $\mathrm{x}$-axis values greater than 1 were more abundant in high-SCC milk, and OTU with x-axis values below 1 were more abundant in low-SCC milk. The letters in front of the bacterial names identify the lowest level of classification $(\mathrm{k}=\mathrm{kingdom}, \mathrm{p}=\mathrm{phylum}, \mathrm{c}=$ class, $\mathrm{o}=$ order, $\mathrm{f}=$ family, and $\mathrm{g}=$ genus). Color version available online.

munity and milk quality parameters (SSC and SPC) based on high-throughput sequencing of the16S rRNA gene. Previous studies focused only on identification of specific bacterial species and their relationships to milk quality parameters, or conducted a simple characterization of the raw milk microbiome. In our study, important spoilage (e.g., Acinetobacter), spore-forming (e.g., Bacillus), and pathogenic (e.g., Staphylococcus) bacteria were identified in the core microbiome of BTM, all of which are bacterial groups of known importance in the dairy industry. We also observed that Streptococcus was the second most abundant bacterial genus detected in samples classified as HSCC, and it was highly correlated with HSPC (highest size effect), which corroborates the existing knowledge that species of Streptococcus are important mastitis pathogens. A negative correlation between the Shannon diversity index and total bacterial load $\left(\log _{10}\right.$ of the copy number of the 16SrRNA gene) was observed, suggesting that a BTM environment with high bacterial count may be dominated by a smaller group of bacterial taxa.

The phylum-level structure of the BTM microbiome detected in the present study is similar to those of previous studies that described the microbial communities of raw milk (Quigley et al., 2013) and BTM (Raats et al., 2011). Furthermore, the common genera previously detected in raw milk, such as Acinetobacter (Gurung et al., 2013), Pseudomonas (von Neubeck et al., 2015), 
Corynebacterium (Quigley et al., 2013), Staphylococcus, and Streptococcus (Park et al., 2007; Zanardi et al., 2014), were also identified in our samples. Additionally, the bacterial taxa that presented the highest abundance in BTM samples were Ruminococcaceae, Acinetobacter, and Enterobacteriaceae. Our results are in line with studies that previously reported Ruminococcaceae in the milk microbiome (Oikonomou et al., 2014; Young et al., 2015). Members of this family have been widely identified in samples across the different anatomical parts of the gastrointestinal tract of dairy cattle (Lima et al., 2015; Mao et al., 2015). Therefore, it has been suggested that microorganisms from maternal gastrointestinal microbiota reach the mammary secretions, contributing to the bacterial components in milk (Young et al., 2015). The existence of the enteromammary pathway in humans and mice has been described, where microbes from the gut lumen travel through the mesenteric lymph nodes and then reach the mammary gland (Perez et al., 2007; Donnet-Hughes et al., 2010; Fernández et al., 2013). The mechanism by which microorganisms cross body sites is not fully understood and may involve immune cells (Perez et al., 2007; Donnet-Hughes et al., 2010). Young et al. (2015) investigated if a similar mechanism was evident in cows and found support for the presence of an endogenous enteromammary pathway during lactation in the cow when the same bacterial taxon (i.e., Ruminococcus genus) was found in milk, blood, and feces of healthy lactating cows. Therefore, contamination by this bacterial taxon during milking and milk storage should be also considered.

Acinetobacter adapts to a variety of environmental conditions, and emerging pathogens have been reported in this genus (Gurung et al., 2013). In the milk production process, the lipolytic and proteolytic activities of

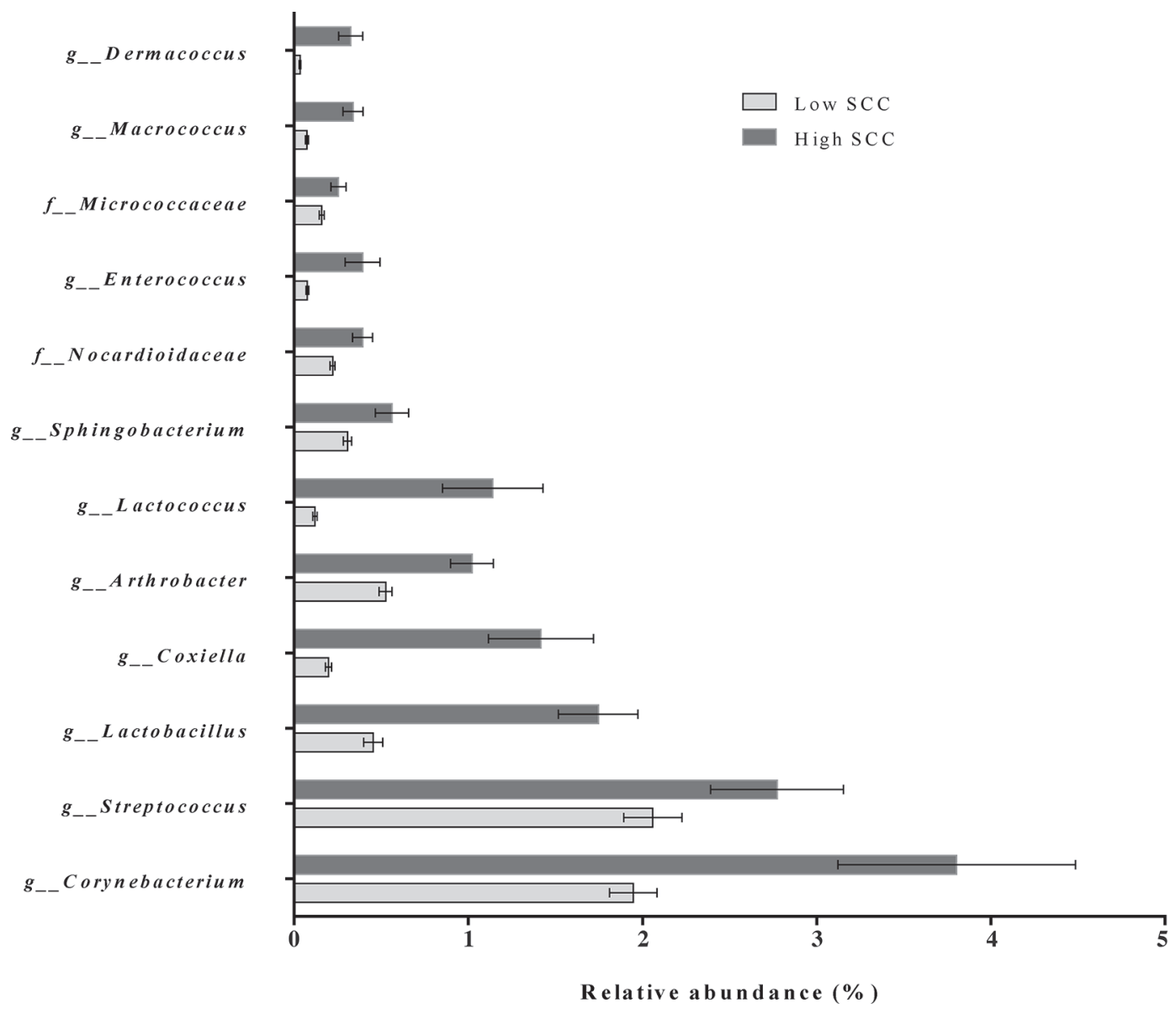

Figure 6. Bar graph depicting the difference of relative abundances between the bulk tank milk samples that were classified as high- and low-SCC $(>200,000$ and $\leq 200,000$, respectively). This graph depicts the taxa that were found in significantly higher relative abundance in highcompared with low-SCC samples. The mean relative abundances ( \pm SEM) are shown for each operational taxonomic unit for low- (light gray bars) and high-SCC samples (dark gray bars). The letters in front of the bacterial names identify the lowest level of classification ( $\mathrm{k}=\mathrm{kingdom}$, $\mathrm{p}=$ phylum, $\mathrm{c}=$ class, $\mathrm{o}=$ order, $\mathrm{f}=$ family, and $\mathrm{g}=$ genus $)$. 


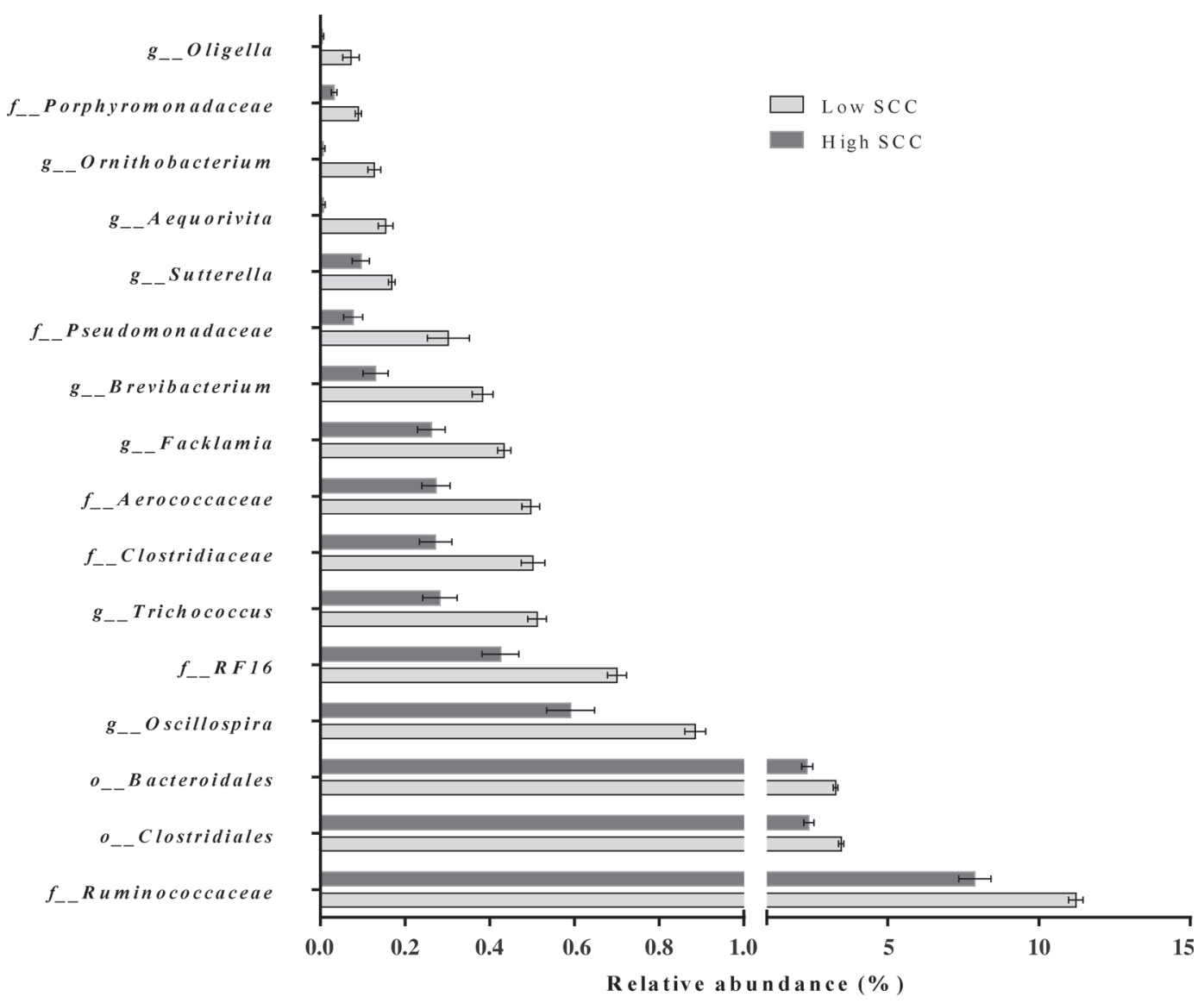

Figure 7. Bar graph depicting the difference of relative abundances between the bulk tank milk samples that were classified as high and low SCC (>200,000 and $\leq 200,000$, respectively). This graph depicts the taxa that were found in significantly higher relative abundance in lowcompared with high-SCC samples. The mean relative abundances $( \pm$ SEM) are shown for each operational taxonomic unit for low- (light gray bars) and high-SCC samples (dark gray bars). The letters in front of the bacterial names identify the lowest level of classification (k $=$ kingdom, $\mathrm{p}=$ phylum, $\mathrm{c}=$ class, $\mathrm{o}=$ order, $\mathrm{f}=$ family, and $\mathrm{g}=$ genus $)$.

Acinetobacter contribute to spoilage of dairy products (Hantsis-Zacharov and Halpern, 2007). Another important group of bacteria related to food safety and spoilage are members of the Enterobacteriaceae family, which can be detected in almost all natural environments and are often associated with intestinal infections (Anand and Griffiths, 2011). Contamination of raw milk by cow feces during milking is common; thus, Enterobacteriaceae have been used as indicators of hygiene and microbial quality (Anand and Griffiths, 2011). Elmoslemany et al. (2009) highlighted the importance of cow and stall hygiene and equipment hygiene to bacteriological quality of bulk tank milk. Management practices have influence in quality milk (Jayarao et al., 2004; Masiello et al., 2014; Miller et al., 2015), characteristics such as use of used automatic milking detachers, bedding material, technique used for teat dipping, and practices pre- and postdipping are relevant (Jayarao et al., 2004). Management practices associated with cow cleanliness may ensure better microbial quality, longer shelf life, of fluid milk (Masiello et al., 2014).

Additionally, in the present study, we observed by using $\mathrm{qPCR}$ that the relative abundances of Acinetobacter and Enterobacteriaceae increase with increasing total bacterial load in BTM samples. As mentioned above, Acinetobacter are psychrotolerant bacteria (Fricker et al., 2011), and within the Enterobacteriaceae family some members, such as Klebsiella, Enterobacter, Citrobacter, and Serratia, do grow very well in refrigerated milk (Anand and Griffiths, 2011).

An interesting finding from our study was the identification of 12 bacterial taxa common to all 19 dairy farms enrolled, suggesting that a core BTM microbiome may exist. Several bacterial taxa identified in the core microbiome have been previously described in raw milk (Hantsis-Zacharov and Halpern, 2007; Oikonomou et al., 2014; Weber et al., 2014; Miller et al., 2015). To our knowledge, ours is the first report describ- 


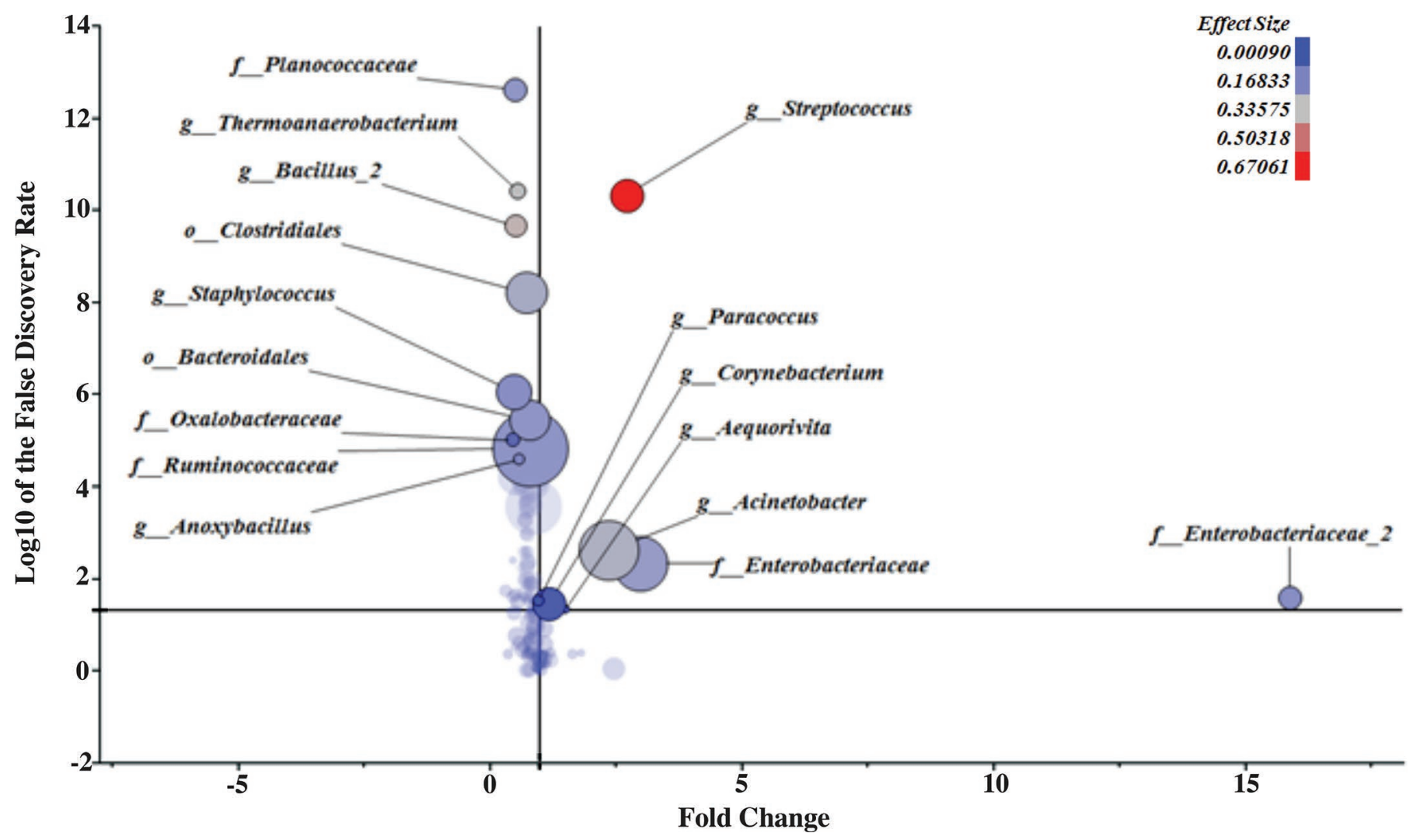

Figure 8. Bubble graph illustrating the operational taxonomic units (OTU) that were significantly associated with the $\log _{10}$ of the SPC. Bulk tank milk samples were divided into high $(>3.6)$ and $\operatorname{low} \log _{10} \mathrm{SPC}(\leq 3.6)$. The graph illustrates the $\log _{10}$ of the false discovery rate along the $\mathrm{y}$-axis and the fold change of the relative abundance of each specific OTU in comparison with high- versus low-log ${ }_{10}-\mathrm{SPC}$ samples along the $\mathrm{x}$-axis. The size of the bubbles represents the overall abundance of each OTU and the colors represent the size of the detected effect $(\mathrm{blue}=$ small effect and red $=$ large effect). OTU with $\mathrm{x}$-axis values greater than 1 were more abundant in high $\log _{10}$-SPC milk, and OTU with $\mathrm{x}$-axis values below 1 were more abundant in $\operatorname{low} \log _{10}$-SPC milk. The letters in front of the bacterial names identify the lowest level of classification ( $\mathrm{k}=$ kingdom, $\mathrm{p}=$ phylum, $\mathrm{c}=$ class, $\mathrm{o}=$ order, $\mathrm{f}=$ family, and $\mathrm{g}=$ genus $)$. Color version available online.

ing 5-7N15 and Thermoanaerobacterium in raw milk samples, both in the milk core microbiome described. $5-7 N 15$ has been identified in fecal samples from dairy cows (Young et al., 2015); however, information regarding this genus is limited. The Thermoanaerobacterium genus has generated interest within the food sector in the last decade due its potential as a contaminant during manufacturing involving high temperatures, because the genus contains thermophilic spore-forming bacteria (Mtimet et al., 2016). Spores present in raw milk can survive pasteurization and other conditions during dairy-product processing (Miller et al., 2015), and the spores can germinate postprocessing to cause dairy-product spoilage (Masiello et al., 2014) or foodborne disease (Bennett et al., 2013). Raw milk has been implicated as an important source of spores produced by psychrotolerant (Masiello et al., 2014; Miller et al., 2015), mesophilic, and thermophilic spore-forming bacteria (Miller et al., 2015).
We identified a high abundance of Ruminococcaceae in all SCC and $\log _{10}$ SPC quartiles; therefore, further studies should be conducted to understand the origin and the role of Ruminococcaceae in milk samples. The observed high abundance of Enterobacteriaceae in the highest quartiles of $\log _{10}$ SPC and SCC can indicate poor hygiene or a high prevalence of mastitis in the herd. In addition, the abundance of Acinetobacter was clearly higher in the fourth quartile of $\log _{10} \mathrm{SPC}$, and the positive correlation between Acinetobacter and total bacterial load that we observed suggests that bacteria within the Acinetobacter genus are an important environment contaminant. This genus is known to cause spoilage (Hantsis-Zacharov and Halpern, 2007) and is also a rare primary cause of mastitis (Oliver and Murinda, 2012). The mean relative abundances of Streptococcus and Corynebacterium increased from the first to the fourth quartiles of SCC, consistent with their importance as etiological agents of mastitis. 
The bacterial genera associated with samples classified as HSCC were Macrococcus, Enterococcus, Coxiella, Lactococcus, Dermacoccus, and Lactobacillus. Enterococcus, Coxiella, and Lactococcus are known mastitis pathogens; however, Macrococcus, Dermacoccus, and Lactobacillus are not associated with bovine mastitis. Dermacoccus was first isolated from human skin and described as Micrococcus (Stackebrandt et al., 1995), Macrococcus is phylogenetically close to the genus Staphylococcus (Baba et al., 2009), and Lactobacillus spp. are known for their beneficial properties (Bouchard et al., 2015). In addition, food-borne illness can be caused by Enterococcus (Giraffa, 2002). The highest relative abundances of Corynebacterium and Streptococcus were encountered in samples classified as HSCC, and both are known to be important mastitis pathogens (Smith et al., 1985; Jayarao et al., 2004; Gonçalves et al., 2016). Species within the genus Streptococcus have been previously associated with increased SCC in BTM samples (Jayarao et al., 2004). Although, Corynebacterium bovis, a contagious pathogen, was already associated with increased SCC in milk samples from dairy cows with subclinical mastitis (Gonçalves et al., 2016), the SCC found in a previous study was lower than the threshold of HSCC used in our experiment. A precedent study, performed by Lam et al. (1997), detected that the prevalence of Corynebacterium spp. may be an indicator of the use of postmilking teat-disinfection; thus, this pathogen may be a potential indicator of hygiene issues in the parlor, which can have an important effect on mammary gland health and consequently on bulk tank SCC. On the other hand, in samples classified as LSCC, Ruminococcaceae, Clostridiales, and Bacteroidales, were the most abundant taxa. These groups, mainly Ruminococcaceae and Bacteroidales, have been previously detected during cold storage of bovine raw milk (Gschwendtner et al., 2016).

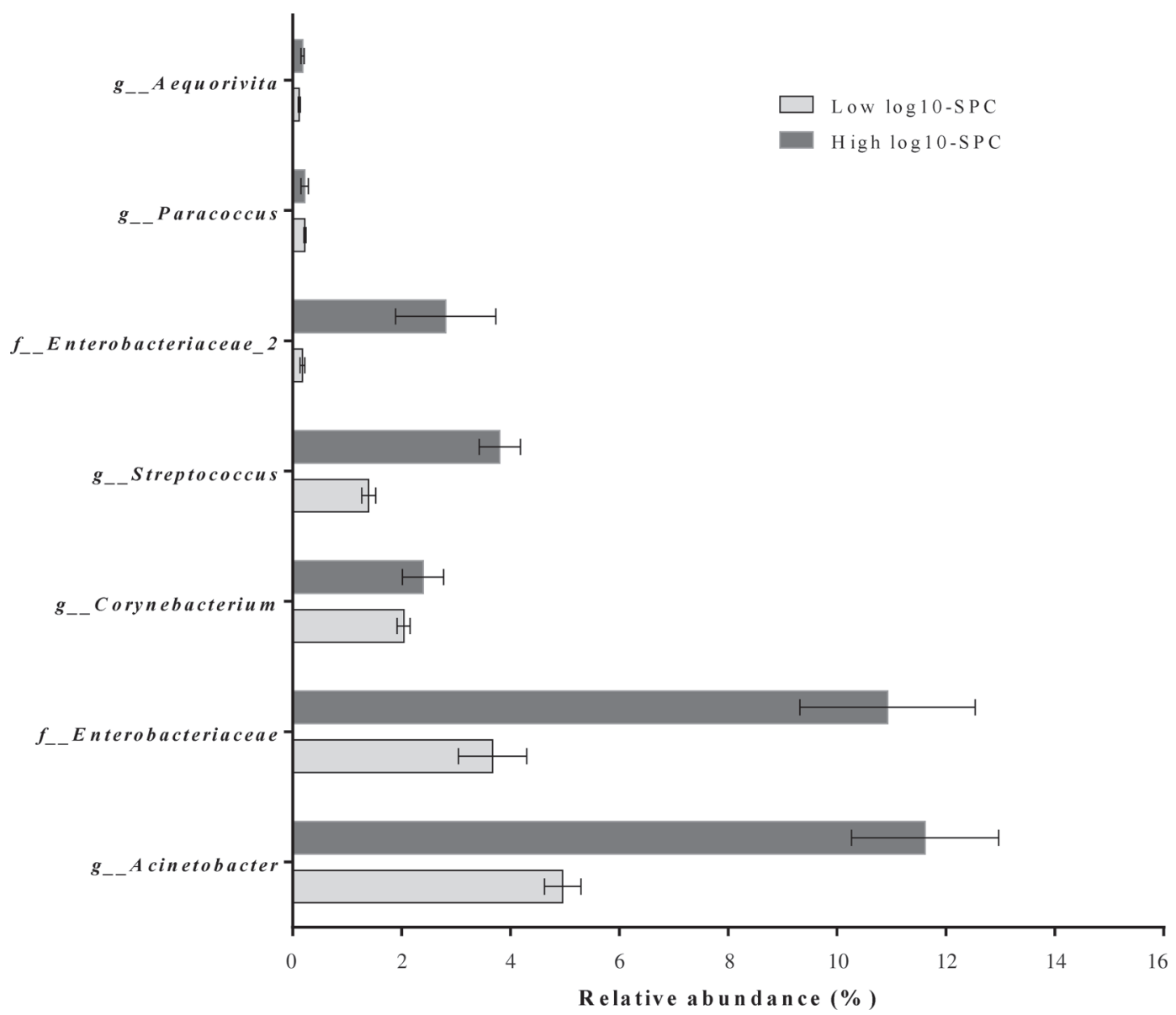

Figure 9. Bar graph depicting differences of relative abundances between the bulk tank milk samples that were classified as high and low $\log _{10}$ of the SPC (>3.6 and $\leq 3.6$, respectively). This graph depicts the bacteria that were found in significantly higher relative abundance in highcompared with $\operatorname{low}_{-} \log _{10}$ SPC samples. The mean relative abundances $( \pm \mathrm{SEM})$ are shown for each operational taxonomic unit for low- (light gray bars) and high- $\log _{10}$ SPC samples (dark gray bars). The letters in front of the bacterial names identify the lowest level of classification (k $=$ kingdom, $\mathrm{p}=$ phylum, $\mathrm{c}=$ class, $\mathrm{o}=$ order, $\mathrm{f}=$ family, and $\mathrm{g}=$ genus $)$. 
In samples classified as HSPC, our microbiome analysis showed HSPC to be associated with a small group of bacterial taxa. In most cases the increase of bacterial count is correlated with unsanitary conditions (Jayarao et al., 2004), which may explain the high prevalence of Enterobacteriaceae in BTM samples classified as HSPC and the positive correlation between relative abundance of Enterobacteriaceae and total bacterial load described in the present study. Presence of coliforms, an important group within this family, is suggestive of fecal contamination in BTM samples or contamination of water used in the cleaning process (Jayarao et al., 2004). Furthermore, some Enterobacteriaceae are environmental mastitis pathogens that access BTM not only from IMI, but also from cow skin, teat ends and skin, bedding, manure, and water (Jayarao et al., 2004). Streptococcus was the bacterial taxon with the highest effect size in samples classified as HSPC. This genus is frequently detected in BTM samples (Zadoks et al., 2004) and includes contagious and environmental mastitis pathogens (Jayarao et al., 2004, Jørgensen et al., 2016). Similarly, Gillespie et al. (2012) reported the highest correlation between SPC and Streptococcus spp. count. In another study, Hayes et al. (2001) found Streptococcus uberis to be associated with increased SPC in BTM samples (Hayes et al., 2001). In summary, Streptococcus abundance was highly correlated with both SCC and SPC, suggesting that this genus remains a very significant problem to the dairy industry and that more preventive actions should be implemented to reduce its incidence. In addition, an important remaining concern is the presence of spore-forming bacteria in milk (Anand and Griffiths, 2011), which may survive pasteurization; indeed, in the present study, we identified spore-forming species in LSPC groups of BTM.

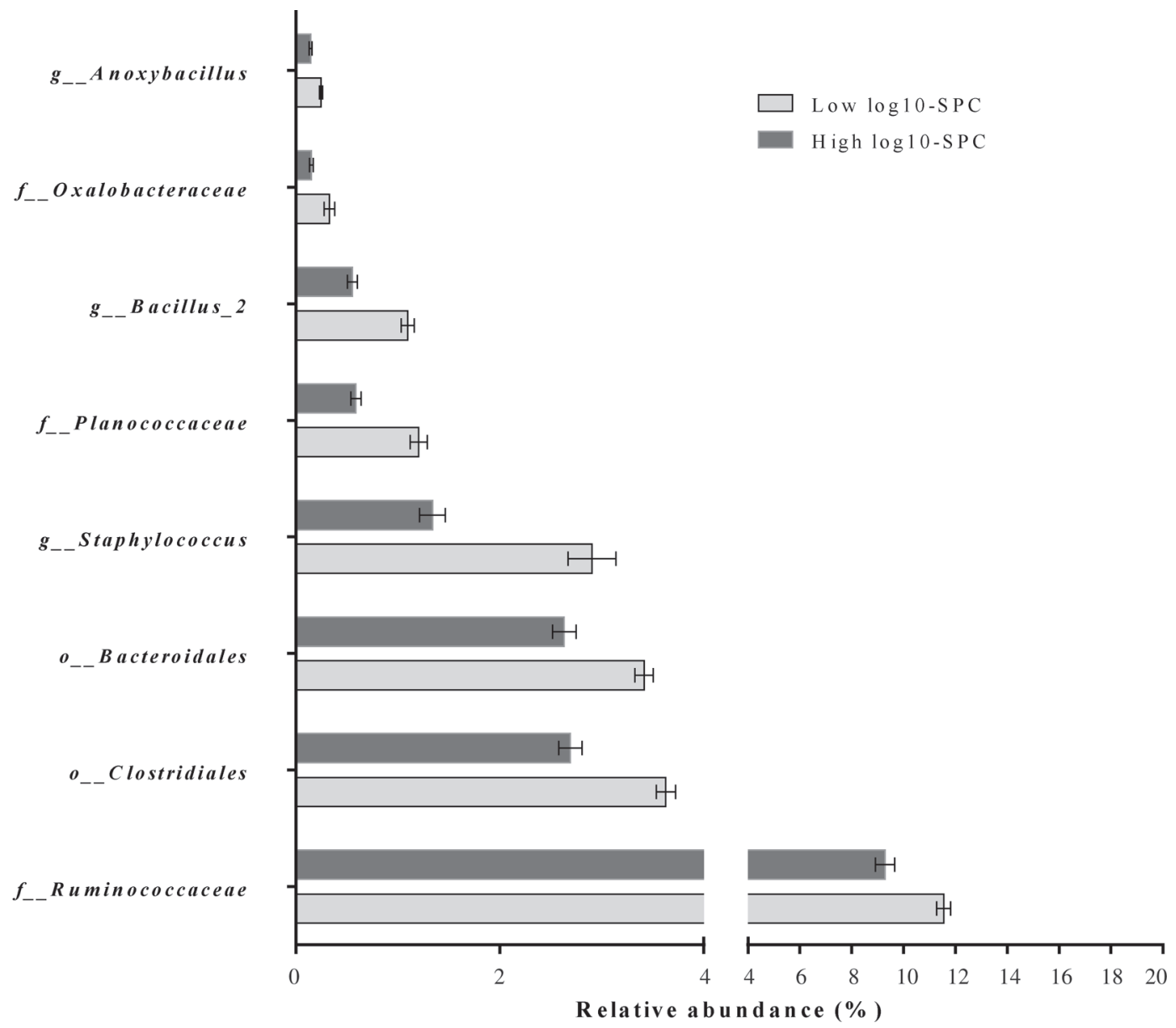

Figure 10. Bar graph depicting differences of relative abundances between the bulk tank milk samples that were classified as high and low $\log _{10}$ of the SPC $(>3.6$ and $\leq 3.6$, respectively). This graph depicts the bacteria that were found in significantly higher relative abundance in lowcompared with high- $\log _{10}$ SPC samples. The mean relative abundances ( \pm SEM) are shown for each operational taxonomic unit for low- (light gray bars) and high- $\log _{10}$ SPC samples (dark gray bars). The letters in front of the bacterial names identify the lowest level of classification (k $=$ kingdom, $\mathrm{p}=$ phylum, $\mathrm{c}=$ class, $\mathrm{o}=$ order, $\mathrm{f}=$ family, and $\mathrm{g}=$ genus). 


\section{CONCLUSIONS}

Our description of the microbiome of BTM samples and its association with milk quality parameters corroborate the current knowledge regarding the bacterial community of raw milk and the effects on milk quality parameters. Bacterial taxa widely studied in milk were among the most abundant identified in our BTM samples, with Ruminococcaceae being the most abundant. Spoilage bacteria, such as Acinetobacter and Pseudomonas, were ubiquitous in BTM for all studied dairy farms. In samples classified as HSPC, Acinetobacter and Enterobacteriaceae presented higher relative abundances, and both increased as bacterial load increased. Spore-forming bacteria (Thermoanaerobacterium and Bacillus) were identified in the core microbiome of BTM, which is a concern to the dairy industry. Among the pathogens associated with SCC and SPC, Streptococcus was highlighted. Other pathogens (e.g., Corynebacterium) were observed at significantly higher relative abundances in the HSCC group when compared with the LSCC group; a similar result was obtained in the analysis of SPC. We also found that the BTM environment is dominated by a smaller group of bacterial taxa in cases with higher bacterial load. For further investigation, we suggest studying the bacterial taxa that were detected at significantly higher relative abundance in BTM samples classified as HSCC (e.g., Lactobacillus, Arthrobacter, and Lactococcus) to verify the influence of these genera on general milk quality and herd health.

\section{ACKNOWLEDGMENTS}

The authors thank CAPES (Coordenação de Aperfeiçoamento de Pessoal de Nível Superior, Brasília, Brazil) for financial support, process number 99999.003177/2015-07. This project was partially sup-

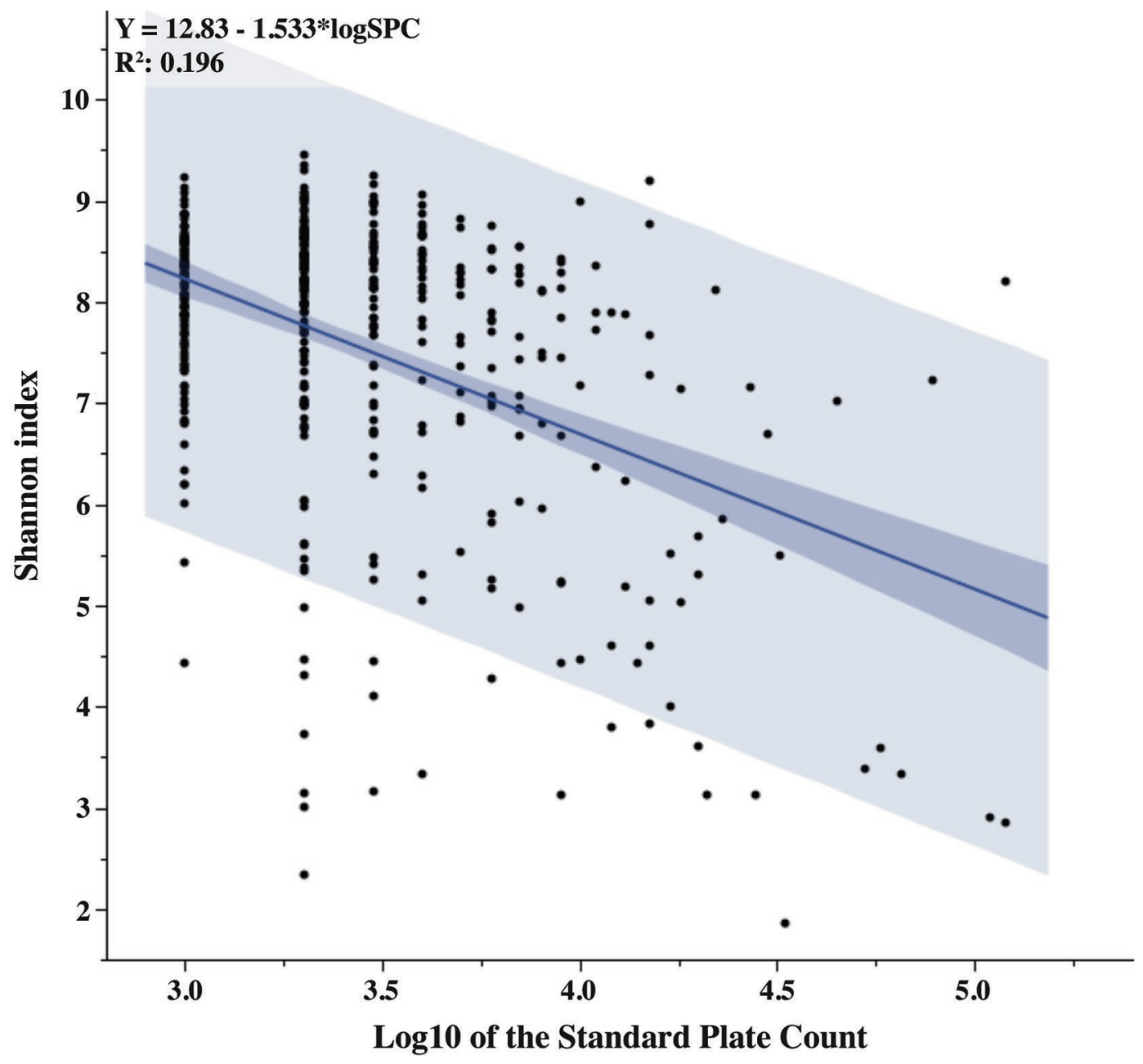

Figure 11. Simple linear regression illustrating the relationship between the Shannon index and $\log _{10}$ of the SPC. The shaded area is the 95\% confidence interval. Color version available online. 

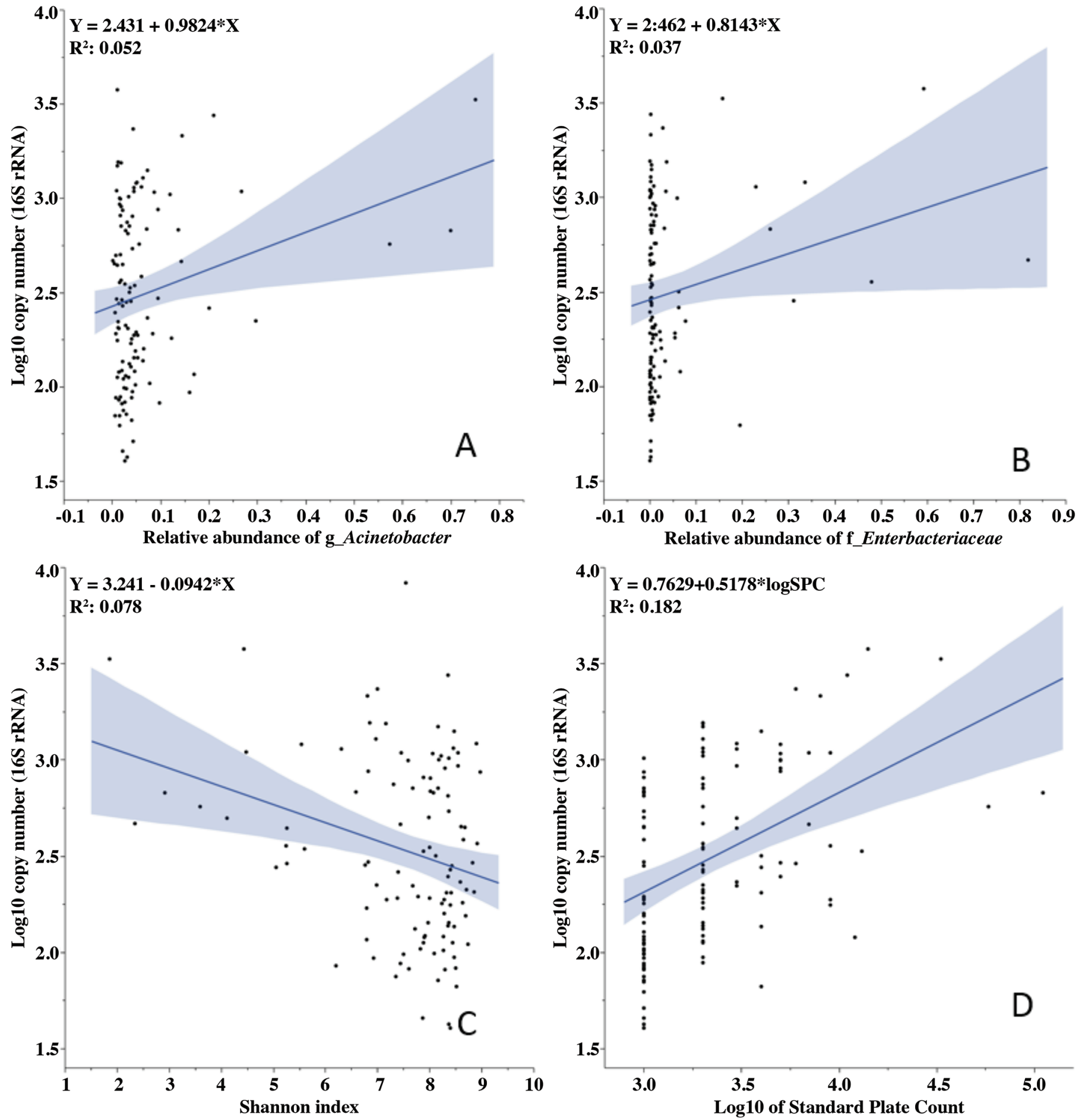

Figure 12. Simple linear regression illustrating the relationship between the $\log _{10}$ copy number (16S rRNA) and relative abundance of genus $(g)$ Acinetobacter (A), relative abundance of family $(f)$ Enterobacteriaceae (B), Shannon index (C), and $\log _{10}$ of the SPC (D). The shaded area is the $95 \%$ confidence interval. Color version available online. 
ported by Agriculture and Food Research Initiative Competitive Grant no. 2013-67015-21233 from the USDA National Institute of Food and Agriculture.

\section{REFERENCES}

Anand, S. K., and M. W. Griffiths. 2011. Pathogens in milk| Enterobacteriaceae. Pages 67-71 in Encyclopedia of Dairy Sciences. 2nd ed. G. W. Smithers, ed. Elsevier Inc. Amsterdam, the Netherlands.

Baba, T., K. Kuwahara-Arai, I. Uchiyama, F. Takeuchi, T. Ito, and K. Hiramatsu. 2009. Complete genome sequence of Macrococcus caseolyticus strain JCSCS5402, [corrected] reflecting the ancestral genome of the human-pathogenic staphylococci. J. Bacteriol. 191:1180-1190.

Barbano, D. M., Y. Ma, and M. V. Santos. 2006. Influence of raw milk quality on fluid milk shelf life. J. Dairy Sci. 89(Suppl. 1):E15-E19.

Benjamini, Y., and Y. Hochberg. 1995. Controlling the false discovery rate: a practical and powerful approach to multiple testing. J. R. Stat. Soc. B 57:289-300.

Bennett, S. D., K. A. Walsh, and L. H. Gould. 2013. Foodborne disease outbreaks caused by Bacillus cereus, Clostridium perfringens, and Staphylococcus aureus - United States, 1998-2008. Clin. Infect. Dis. $57: 425-433$.

Bokulich, N. A., S. Subramanian, J. J. Faith, D. Gevers, J. I. Gordon, R. Knight, D. A. Mills, and J. G. Caporaso. 2013. Quality-filtering vastly improves diversity estimates from Illumina amplicon sequencing. Nat. Methods 10:57-59.

Bouchard, D. S., B. Seridan, T. Saraoui, L. Rault, P. Germon, C. Gonzalez-Moreno, F. M. Nader-Macias, D. Baud, P. François, V. Chuat, F. Chain, P. Langella, J. Nicoli, Y. Le Loir, and S. Even. 2015. Lactic Acid Bacteria isolated from bovine mammary microbiota: Potential allies against bovine mastitis. PLoS One 10:e0144831.

Caporaso, J. G., J. Kuczynski, J. Stombaugh, K. Bittinger, F. D. Bushman, E. K. Costello, N. Fierer, A. G. Peña, J. K. Goodrich, J. I. Gordon, G. A. Huttley, S. T. Kelley, D. Knights, J. E. Koenig, R. E. Ley, C. A. Lozupone, D. McDonald, B. D. Muegge, M. Pirrung, J. Reeder, J. R. Sevinsky, P. J. Turnbaugh, W. A. Walters, J. Widmann, T. Yatsunenko, J. Zaneveld, and R. Knight. 2010. QIIME allows analysis of high-throughput community sequencing data. Nat. Methods 7:335-336.

Caporaso, J. G., C. L. Lauber, W. A. Walters, D. Berg-Lyons, J. Huntley, N. Fierer, S. M. Owens, J. Betley, L. Fraser, M. Bauer, N. Gormley, J. A. Gilbert, G. Smith, and R. Knight. 2012. Ultrahigh-throughput microbial community analysis on the Illumina HiSeq and MiSeq platforms. ISME J. 6:1621-1624.

Donnet-Hughes, A., P. F. Perez, J. Doré, M. Leclerc, F. Levenez, J. Benyacoub, P. Serrant, I. Segura-Roggero, and E. J. Schiffrin. 2010. Potential role of the intestinal microbiota of the mother in neonatal immune education. Proc. Nutr. Soc. 69:407-415.

Edgar, R. C. 2010. Search and clustering orders of magnitude faster than BLAST. Bioinformatics 26:2460-2461.

Elmoslemany, A. M., G. P. Keefe, I. R. Dohoo, and B. M. Jayarao. 2009. Risk factors for bacteriological quality of bulk tank milk in Prince Edward Island dairy herds. Part 2: bacteria count-specific risk factors. J. Dairy Sci. 92:2644-2652.

Fernández, L., S. Langa, V. Martín, A. Maldonado, E. Jiménez, R. Martín, and J. M. Rodríguez. 2013. The human milk microbiota: Origin and potential roles in health and disease. Pharmacol. Res. 69:1-10.

Fricker, M., B. Skånseng, K. Rudi, B. Stessl, and M. Ehling-Schulz. 2011. Shift from farm to dairy tank milk microbiota revealed by a polyphasic approach is independent from geographical origin. Int. J. Food Microbiol. 145(Suppl. 1):S24-S30.

Gillespie, B. E., M. J. Lewis, S. Boonyayatra, M. L. Maxwell, A. Saxton, S. P. Oliver, and R. A. Almeida. 2012. Short communication: Evaluation of bulk tank milk microbiological quality of nine dairy farms in Tennessee. J. Dairy Sci. 95:4275-4279.

Giraffa, G. 2002. Enterococci from foods. FEMS Microbiol. Rev. 26:163-171.
Gonçalves, J. L., T. Tomazi, J. R. Barreiro, D. C. Beuron, M. A. Arcari, S. H. Lee, C. M. Martins, J. P. Araújo Junior., and M. V. Santos. 2016. Effects of bovine subclinical mastitis caused by Corynebacterium spp. on somatic cell count, milk yield and composition by comparing contralateral quarters. Vet. J. 209:87-92.

Gschwendtner, S., T. Alatossava, S. Kublik, M. M. Fuka, M. Schloter, and P. Munsch-Alatossava. 2016. N2 gas flushing alleviates the loss of bacterial diversity and inhibits psychrotrophic pseudomonas during the cold storage of bovine raw milk. PLoS One 11:e0146015.

Gurung, M., H. M. Nam, M. D. Tamang, M. H. Chae, G. C. Jang, S. C. Jung, and S. K. Lim. 2013. Prevalence and antimicrobial susceptibility of Acinetobacter from raw bulk tank milk in Korea. J. Dairy Sci. 96:1997-2002.

Hantsis-Zacharov, E., and M. Halpern. 2007. Culturable psychrotrophic bacterial communities in raw milk and their proteolytic and lipolytic traits. Appl. Environ. Microbiol. 73:7162-7168.

Hayes, M. C., R. D. Ralyea, S. C. Murphy, N. R. Carey, J. M. Scarlett, and K. J. Boor. 2001. Identification and characterization of elevated microbial counts in bulk tank raw milk. J. Dairy Sci. 84:292-298.

International Dairy Federation. 1991. IDF Standard 100B:1991 (-Milk and milk products: Enumeration of microorganisms. IDF, Brussels, Belgium.).

Jayarao, B. M., S. R. Pillai, A. A. Sawant, D. R. Wolfgang, and N. V. Hegde. 2004. Guidelines for monitoring bulk tank milk somatic cell and bacterial counts. J. Dairy Sci. 87:3561-3573.

Jørgensen, H. J., A. B. Nordstoga, S. Sviland, R. N. Zadoks, L. Sølverød, B. Kvitle, and T. Mørk. 2016. Streptococcus agalactiae in the environment of bovine dairy herds - Rewriting the textbooks? Vet. Microbiol. 184:64-72.

Katholm, J., T. W. Bennedsgaard, M. T. Koskinen, and E. Rattenborg. 2012. Quality of bulk tank milk samples from Danish dairy herds based on real-time polymerase chain reaction identification of mastitis pathogens. J. Dairy Sci. 95:5702-5708.

Kuang, Y., K. Tani, A. J. Synnott, K. Ohshima, H. Higuchi, H. Nagahata, and Y. Tanji. 2009. Characterization of bacterial population of raw milk from bovine mastitis by culture-independent PCRDGGE method. Biochem. Eng. J. 45:76-81.

Lam, T. J. G. M., J. H. van Vliet, Y. H. Schukken, F. J. Grommers, A. van Velden-Russcher, H. W. Barkema, and A. Brand. 1997. The effect of discontinuation of postmilking teat disinfection in low somatic cell count herds. II Dynamics of intramammary infections. Vet. Q. 19:47-53.

Li, N., R. Richoux, M. Boutinaud, P. Martin, and V. Gagnaire. 2014. Role of somatic cells on dairy processes and products: A review. Dairy Sci. Technol. 94:517-538.

Lima, F. S., G. Oikonomou, S. F. Lima, M. L. Bicalho, E. K. Ganda, J. C. Filho, G. Lorenzo, P. Trojacanec, and R. C. Bicalho. 2015. Prepartum and postpartum rumen fluid microbiomes: Characterization and correlation with production traits in dairy cows. Appl. Environ. Microbiol. 81:1327-1337.

Mao, S., M. Zhang, J. Liu, and W. Zhu. 2015. Characterising the bacterial microbiota across the gastrointestinal tracts of dairy cattle: Membership and potential function. Sci. Rep. 5:16116.

Masiello, S. N., N. H. Martin, R. D. Watters, D. M. Galton, Y. H. Schukken, M. Wiedmann, and K. J. Boor. 2014. Identification of dairy farm management practices associated with the presence of psychrotolerant sporeformers in bulk tank milk. J. Dairy Sci. 97:4083-4096.

McDonald, D., M. N. Price, J. Goodrich, E. P. Nawrocki, T. Z. DeSantis, A. Probst, G. L. Andersen, R. Knight, and P. Hugenholtz. 2012. An improved Greengenes taxonomy with explicit ranks for ecological and evolutionary analyses of bacteria and archaea. ISME J. 6:610-618.

Miller, R. A., D. J. Kent, K. J. Boor, N. H. Martin, and M. Wiedmann. 2015. Different management practices are associated with mesophilic and thermophilic spore levels in bulk tank raw milk. J. Dairy Sci. 98:4338-4351.

Mtimet, N., S. Guégan, L. Durand, A. G. Mathot, L. Venaille, I. Leguérinel, L. Coroller, and O. Couvert. 2016. Effect of $\mathrm{pH}$ on 
Thermoanaerobacterium thermosaccharolyticum DSM 571 growth, spore heat resistance and recovery. Food Microbiol. 55:64-72.

Nightingale, C., K. Dhuyvetter, R. Mitchell, and Y. Schukken. 2008. Influence of variable milk quality premiums on observed milk quality. J. Dairy Sci. 91:1236-1244.

Nonnenmacher, C., A. Dalpke, R. Mutters, and K. Heeg. 2004. Quantitative detection of periodontopathogens by real-time PCR. J. Microbiol. Methods 59:117-125.

Oikonomou, G., M. L. Bicalho, E. Meira, R. E. Rossi, C. Foditsch, V. S. Machado, A. G. Teixeira, C. Santisteban, Y. H. Schukken, and R. C. Bicalho. 2014. Microbiota of cow's milk: Distinguishing healthy, sub-clinically and clinically diseased quarters. PLoS One 9:e85904.

Oliver, S. P., and S. E. Murinda. 2012. Antimicrobial resistance of mastitis pathogens. Vet. Clin. North Am. Food Anim. Pract. $28: 165-185$.

Park, Y. K., H. C. Koo, S. H. Kim, S. Y. Hwang, W. K. Jung, J. M. Kim, S. Shin, R. T. Kim, and Y. H. Park. 2007. The analysis of milk components and pathogenic bacteria isolated from bovine raw milk in Korea. J. Dairy Sci. 90:5405-5414.

Perez, P. F., J. Doré, M. Leclerc, F. Levenez, J. Benyacoub, P. Serrant, I. Segura-Roggero, E. J. Schiffrin, and A. Donnet-Hughes. 2007. Bacterial imprinting of the neonatal immune system: Lessons from maternal cells? Pediatrics 119:e724-e732.

Quigley, L., R. McCarthy, O. O'Sullivan, T. P. Beresford, G. F. Fitzgerald, R. P. Ross, C. Stanton, and P. D. Cotter. 2013. The microbial content of raw and pasteurized cow milk as determined by molecular approaches. J. Dairy Sci. 96:4928-4937.

Raats, D., M. Offek, D. Minz, and M. Halpern. 2011. Molecular analysis of bacterial communities in raw cow milk and the impact of refrigeration on its structure and dynamics. Food Microbiol 28:465-471.

Smith, K. L., D. A. Todhunter, and P. S. Schoenberger. 1985. Environmental mastitis: Cause, prevalence, prevention. J. Dairy Sci. 68:1531-1553.

Stackebrandt, E., C. Koch, O. Gvozdiak, and P. Schumann. 1995. Taxonomic dissection of the genus Micrococcus: Kocuria gen. nov. Nesterenkonia gen. nov., Kytococcus gen. nov., Dermacoccus gen. nov., and Micrococcus Cohn 1872 gen. emend. Int. J. Syst. Bacteriol. 45:682-692.

von Neubeck, M., C. Baur, M. Krewinkel, M. Stoeckel, B. Kranz, T. Stressler, L. Fischer, J. Hinrichs, S. Scherer, and M. Wenning. 2015. Biodiversity of refrigerated raw milk microbiota and their enzymatic spoilage potential. Int. J. Food Microbiol. 211:57-65.

Weber, M., J. Geißert, M. Kruse, and A. Lipski. 2014. Comparative analysis of bacterial community composition in bulk tank raw milk by culture-dependent and culture-independent methods using the viability dye propidium monoazide. J. Dairy Sci. 97:6761-6776.

Young, W., B. C. Hine, O. A. Wallace, M. Callaghan, and R. Bibiloni. 2015. Transfer of intestinal bacterial components to mammary secretions in the cow. PeerJ 3:e888.

Zadoks, R. N., R. N. González, K. J. Boor, and Y. H. Schukken. 2004 Mastitis-causing streptococci are important contributors to bacterial counts in raw bulk tank milk. J. Food Prot. 67:2644-2650.

Zanardi, G., A. Caminiti, G. Delle Donne, P. Moroni, A. Santi, G. Galletti, M. Tamba, G. Bolzoni, and L. Bertocchi. 2014. Short communication: Comparing real-time $\mathrm{PCR}$ and bacteriological cultures for Streptococcus agalactiae and Staphylococcus aureus in bulk-tank milk samples. J. Dairy Sci. 97:5592-5598. 